\title{
The informational roles and psychological health of members of I0 oncology multidisciplinary teams in the UK
}

\author{
S Catt ${ }^{*, 1}$, L Fallowfield', V Jenkins', C Langridge' and A Cox' \\ 'Cancer Research UK, Psychosocial Oncology Group, Brighton \& Sussex Medical School, University of Sussex, Falmer, Brighton BNI 9QG, UK
}

\begin{abstract}
We report here the different roles undertaken by the members of 10 multidisciplinary cancer teams in conveying information to patients during their care. Team members completed an Informational Roles Questionnaire measuring an individual's perception of their major role and that of their colleagues in giving information to patients. They also completed two standard psychological health measures, the General Health Questionnaire and Maslach Burnout Inventory. The information giving roles of the surgeon, oncologist, radiologist and clinical nurse specialist were well recognised by their colleagues; however, other team members' roles were more ambiguous and less well understood. The clinical nurse specialist provided the broadest information coverage for patients. Few professional groups regularly informed patients about clinical trials and family history and the clinical nurse specialist was often the only person to deal with patients' sexual well being, consequently these areas are likely to receive poor coverage. Probable psychiatric morbidity $(\mathrm{GHQ} \geqslant 4)$ in teams ranged from 5 to 27\%. High levels of emotional exhaustion were particularly apparent in team leaders and nurses and feelings of low levels of personal accomplishment were prevalent in the histopathologists and radiologists. Putative benefits to patients and healthcare professionals from multidisciplinary team working may not be realised without investment in team training.

British Journal of Cancer (2005) 93, 1092 - 1097. doi:I0.1038/sj.bjc.66028I6 www.bjcancer.com

Published online 18 October 2005

(C) 2005 Cancer Research UK
\end{abstract}

Keywords: multidisciplinary teams; psychological well being; burnout

The multidisciplinary team (MDT) evolved in response to the increasing complexities of patient care, with each discipline contributing his/her particular skills and knowledge for the benefit of the patient (Hall and Weaver, 2001). Since the publication of the Calman-Hine report concerning reorganisation of cancer services in the UK, many centres have adopted a MDT approach with the aim of providing the patient with the best care (Calman and Hine, 1995). In the Improving Outcomes Guidance (NHS Executive, 1999, 2002, 2004) the core professions typically involved in providing multidisciplinary care to patients with cancer are surgery, oncology, pathology, radiology and nursing. Additionally it may include, palliative care, psychiatry/psychology, genetics and plastic surgery. The concept of a MDT should not merely be a group of professionals who work essentially independently and occasionally liase with one another (Miller et al, 2001). Effective interprofessional team working needs the evolution of a shared team culture, open communication, mutual respect for all the practitioners and equal value to be placed on their contribution to current team practices (Freeman et al, 2000). It is suggested that this can only be achieved when each member of the team understands the others' contributions to care, as well as understanding how and why they practise in the way they do and this requires group process to be nurtured (Miller et al, 2001). The

*Correspondence: Dr S Catt; E-mail: S.L.Catt@sussex.ac.uk Received 13 July 2005; revised 15 September 2005; accepted 16 September 2005; published online 18 October 2005 expectation is that successful multidisciplinary teamwork is beneficial both for the patient and members of the team.

Early retrospective reviews of cancer registries (Junor et al, 1994; Sainsbury et al, 1995) concluded survival prospects for patients were better when a multidisciplinary approach to treatment and care had been employed. Similarly combined modality therapy was emerging as the treatment of choice for patients with breast cancer leading the way to multidisciplinary management (Hortobagyi, 1994). An examination of the relationship between cancer teams and the quality of care delivered showed MDT working benefited patients through improved access to, and use of, standardised and up-to-date therapy (Landheer et al, 2001). Papers outline the necessity of a multidisciplinary approach for optimizing outcome in patients with cancer (Van Laethem et al, 2001; Blumberg and Ramanathan, 2002) and some evidence exists to show that specialized multidisciplinary units increase the efficacy and efficiency of the management of patients with cancer (Shankar et al, 2001; Soriano et al, 2002; Haward et al, 2003). However, quality of clinical care and team effectiveness has been shown to be related to team composition, working methods and workloads (Haward et al, 2003).

Ramirez et al (1996) identified poor communication and a lack of management skills training as major factors leading to burnout and psychiatric morbidity in UK consultants. The Maslach Burnout Inventory (MBI) was used to assess the three components of 'burnout' (emotional exhaustion, depersonalisation and low personal accomplishment) and the General Health Questionnaire (GHQ-12) to measure the consultants' psychiatric morbidity and results showed that radiologists exhibited the highest level of 
burnout in terms of low personal accomplishment while $27 \%$ of consultants had a GHQ-12 score of 4 or more (indicating likely psychiatric morbidity). These data have been recently up-dated with longitudinal follow-up results showing that the prevalence of psychiatric morbidity in these UK consultants had risen to $32 \%$ and that emotional exhaustion had increased from $32 \%$ in 1994 to $40 \%$ in 2002 (Taylor et al, 2005). The authors relate this decline in mental health to increased job stress without a comparable increase in job satisfaction and noted that this was especially marked in clinical and surgical oncologists. 'Burnout' symptoms can include dysfunctional attitudes and behaviours towards colleagues, which in turn will have a detrimental effect on team functioning, communication and patient care.

However, research in the primary healthcare setting has shown that those working within a supportive, well-functioning team, benefited from better mental health and increased team effectiveness (Carter and West, 1999). Complex tasks were accomplished more easily when professionals within the healthcare teams had clear goals, were cooperative and mutually supportive of one another and aware of each other's role (Firth-Cozens, 1999; Payne, 1999). An extensive study covering a 3-year period, focusing on three types of MDT (100 primary healthcare teams, 113 community mental healthcare teams and 193 secondary healthcare teams) showed that better team functioning was associated with better mental health (Borrill et al, 2000). This finding has been reiterated by Haward et al (2003) who reported a beneficial effect of team working on mental health in breast cancer teams, where prevalence for minor psychiatric morbidity measured using the GHQ-12 was as low as $15.7 \%$ across all teams, a figure below that of $18 \%$ given for the UK general population (Taylor et al, 1995). These findings contrast with rates of $28-32 \%$ given for a cohort of UK consultants (Ramirez et al, 1996; Taylor et al, 2005) and those of past data for NHS trust staff in general where an incidence of $27 \%$ has been reported (Wall et al, 1997). Mullarky et al (1999) have reported incidences in community mental health teams, secondary-care teams and primary healthcare teams of 26,23 and $22 \%$, respectively.

The Improving Outcomes Guidance (NHS Executive, 1999, 2002, 2004) makes explicit recommendations about communication between healthcare professionals within a MDT and between themselves and patients. However, there is little available data on the advantages and disadvantages of a MDT approach to communication within cancer care. Anecdotal evidence from hospitals and medical defence organisations suggests poor communication can result in complaints and litigation. Reports from the USA demonstrate that a considerable proportion of lawsuits originate from misunderstandings, and not treatment errors (Gorney, 1999; Krause et al, 2001). There is increasing evidence that effective communication is a critical means by which doctors can assist their patients to achieve the best outcomes (Boyle et al, 2004). Audits have been performed to determine the accuracy and consistency of information delivered to breast cancer patients within the healthcare system (Hughes and Bradburn, 1996; Harris, 1997). Both reports showed that the provision and consistency of information presented to the patient differed within the health team. Patients in these surveys stated that they received insufficient information and noted that there was poor communication between the healthcare professionals. Early work concerning communication within breast cancer teams revealed a lack of interdisciplinary awareness of team members' roles and an inability to identify the team leader by a significant minority of MDT members (Jenkins et al, 2001).

We present results on healthcare professionals who participated in a Cancer Research UK funded study looking at MDT communication. The aims of the assessments carried out with MDT members were (1) to describe team members informationgiving roles, (2) to identify the strengths and weaknesses of communication within oncology MDTs in terms of members information giving roles and (3) to assess team members mental health and compare it with previously published data.

\section{MATERIALS AND METHODS}

Five breast, three colorectal and two gynaecology multidisciplinary cancer teams ranging in size from eight to 21 members, recruited from England, Scotland and Wales took part in the study. Each team identified their own regular members; the only stipulation made by the researchers was that all must be attendees at the weekly MDT meetings. The professional make-up of each team is given in Table 1. Team members read an information sheet and gave written consent before participating. The study had multiple regional and local ethical approvals.

Team members completed the Informational Roles Questionnaire (IRQ) (Jenkins et al, 2001) which measures healthcare professionals perceptions of their own role and their awareness of their colleagues' roles in providing information to the patient during their treatment and care. The list of areas covered varied by cancer site but typically included: talking about diagnostic tests,

Table I Team composition

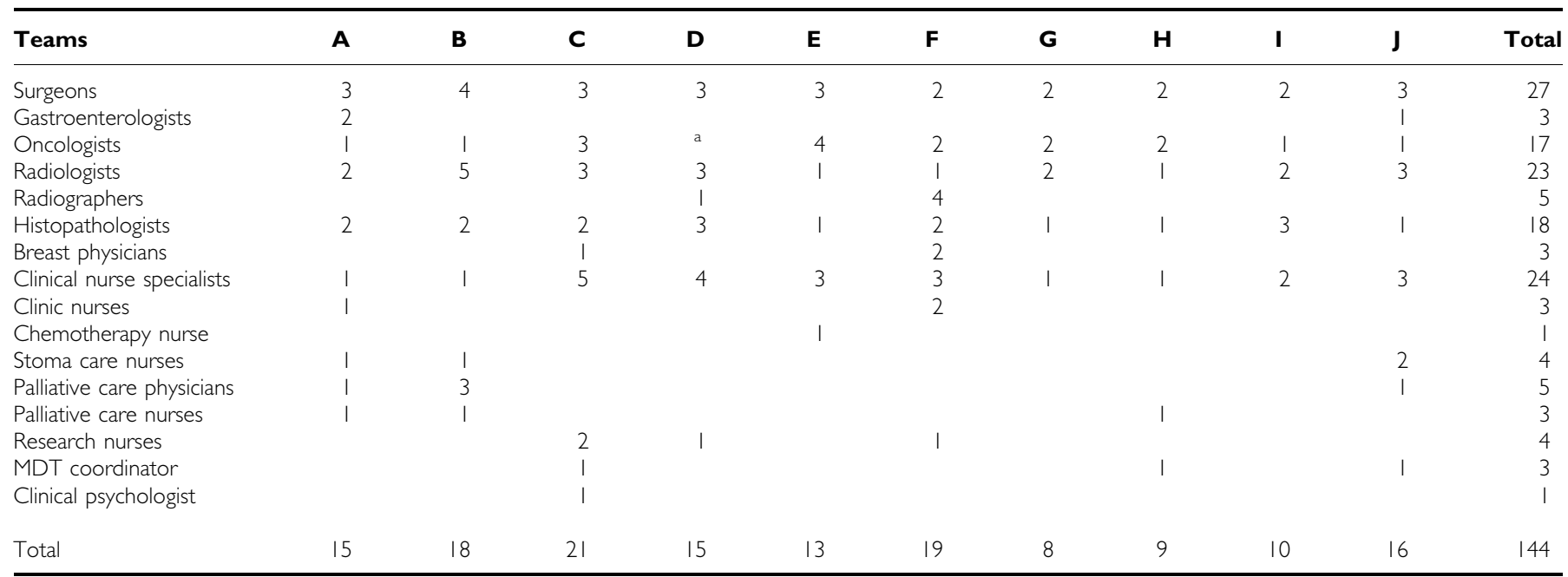

${ }^{a}$ Team $\mathrm{D}$ had one oncologist who declined to participate. 
giving the diagnosis of cancer, discussing surgery, radiotherapy, chemotherapy, prognosis, clinical trials, family history and the provision of written materials. Team members were also asked to indicate whether they and which of their colleagues have a regular role in discussing patient problems in each of five areas of psychosocial concern: (1) physical, (2) functional, (3) sexual, (4) social and (5) emotional well being. They also completed two measures of psychological well being; the 12-item GHQ-12 and the MBI. The GHQ-12 is a self-report questionnaire specifically designed to screen for nonpsychotic psychiatric disorder, it is well validated and has been widely used in samples of healthcare professionals. It measures 12 symptoms of minor psychiatric morbidity (e.g., depression, loss of confidence, sleep disturbance) and these are rated according to whether they have been experienced 'not at all', 'the same as usual', 'rather more than usual', or 'much more than usual' in the past few weeks. Individuals scoring above a threshold of $\geqslant 4$ are highly likely to merit a diagnosis of clinical anxiety or depression according to studies validating the GHQ-12 against standardized psychiatric interviews (Goldberg and Williams, 1988). The MBI (Maslach et al, 1996) is also a self-report questionnaire used to measure the effect that working closely with people in an emotionally demanding role has on a person's mental health. The inventory has three dimensions each of which are reported on:

- Emotional Exhaustion (EE) - the degree to which a person feels emotionally overextended and exhausted by their work.

- Depersonalisation $(D P)$ - the degree to which a person has developed feelings of indifference and cynical attitudes toward recipients of the care, treatment, instruction or service they provide to others in their work.

- Personal Accomplishment (PA) - the degree to which a person gains feelings of competence and successful achievement in their work.

\section{RESULTS}

Results from the IRQ are expressed in tabulation form so that percentage of agreement about what information-giving areas are covered by a role can be examined. Responses to the IRQ allow two views to be represented for each information-giving role and these two views can be compared with each other. The two views of interest are (1) what individuals within a specialist group, for example, surgeons, agree they talk to patients about, referred to as the 'speciality view' and (2) what the rest of the team members believe the surgeons talk to the patients about, referred to as the 'colleagues view'. Consistency within a professional group can be scrutinised as well as looking for congruence between other team member's expectations of a role and the picture given by those individuals who actually carry out the job. Additionally, tabulation allows examination across the speciality views, which can reveal overlaps and gaps in information giving. Tables $2 \mathrm{a}$ and $2 \mathrm{~b}$ show the information-giving roles by professional group comparing each individual speciality's view of their role with the view of their informational role held by the other team members. In Table $2 \mathrm{a}$ professions that are well recognised by team members are presented. For example, all of the surgeons agree they discuss prognosis and $96 \%$ of their colleagues expected this, conversely few surgeons gave out leaflets but this was consistent with few of their colleagues believing they did. Table $2 b$ on the other hand gives examples of specialities that are more ambiguous and less well understood by team members. An example includes the fact that all of the clinic nurses regularly discuss physical, functional, social and emotional well being with patients yet few of their colleagues showed any awareness of this.

It should be noted that results are purely descriptive and that statistical testing of consistency between a 'speciality view' and the 'colleagues view' was not considered appropriate due to the small numbers and multiple comparisons that would be involved in such an analysis.

Table 3 shows the number of different professions regularly covering each information area. In all, 12 out of 14 professions regularly talked to patients about physical well being, in contrast only three and four, respectively, recognised the discussion of clinical trials and family history as their responsibility. Although five professions provided information on sexual well being only one afforded guaranteed access to all patients and this was the clinical nurse specialist. Table 3 also shows that the clinical nurse

Table $\mathbf{2 a}$ Information roles speciality vs colleagues view

\begin{tabular}{|c|c|c|c|c|c|c|c|c|}
\hline & \multicolumn{2}{|c|}{ Surgeon role } & \multicolumn{2}{|c|}{ Oncologist role } & \multicolumn{2}{|c|}{ Radiologist role } & \multicolumn{2}{|c|}{ Clinical nurse specialist role } \\
\hline & $\begin{array}{l}{ }^{\text {a}} \text { Speciality } \\
\text { view }\end{array}$ & $\begin{array}{l}{ }^{b} \text { Colleagues } \\
\text { view }\end{array}$ & $\begin{array}{l}\text { Speciality } \\
\text { view }\end{array}$ & $\begin{array}{c}\text { Colleagues } \\
\text { view }\end{array}$ & $\begin{array}{l}\text { Speciality } \\
\text { view }\end{array}$ & $\begin{array}{c}\text { Colleagues } \\
\text { view }\end{array}$ & $\begin{array}{l}\text { Speciality } \\
\text { view }\end{array}$ & $\begin{array}{c}\text { Colleagues } \\
\text { view }\end{array}$ \\
\hline Total $n$ & 27 & 110 & 17 & 121 & 23 & 117 & 23 & 113 \\
\hline Missing data & & 7 & & 6 & & 4 & 1 & 7 \\
\hline Explaining tests & $27(100 \%)$ & $108(98 \%)$ & || (65\%) & $85(70 \%)$ & $21(9 \mid \%)$ & $97(83 \%)$ & $19(83 \%)$ & $103(9 \mid \%)$ \\
\hline Giving test results & $27(100 \%)$ & $107(97 \%)$ & $13(76 \%)$ & $91(74 \%)$ & $14(61 \%)$ & 73 (62\%) & $18(78 \%)$ & $93(82 \%)$ \\
\hline Surgery & $27(100 \%)$ & $108(98 \%)$ & $3(18 \%)$ & $33(27 \%)$ & $3(13 \%)$ & $12(10 \%)$ & $20(87 \%)$ & $102(90 \%)$ \\
\hline Radiotherapy & $20(74 \%)$ & $80(73 \%)$ & $15(88 \%)$ & $117(97 \%)$ & 0 & $10(9 \%)$ & $21(91 \%)$ & $87(77 \%)$ \\
\hline Chemotherapy & $21(78 \%)$ & 79 (72\%) & $17(100 \%)$ & $116(96 \%)$ & 0 & $6(5 \%)$ & $23(100 \%)$ & $91(81 \%)$ \\
\hline $\begin{array}{l}\text { Hormone therapy (applies to } \\
\text { breast teams only) }\end{array}$ & $13 / 13(100 \%)$ & $55 / 62(89 \%)$ & $10 / 10(100 \%)$ & $61 / 66(92 \%)$ & $0 / 10$ & $0 / 66$ & $16 / 16(100 \%)$ & $51 / 59(86 \%)$ \\
\hline Prognosis & 27 (100\%) & $106(96 \%)$ & $17(100 \%)$ & 115 (95\%) & $3(13 \%)$ & $10(9 \%)$ & 17 (74\%) & 75 (66\%) \\
\hline Clinical trials & $17(63 \%)$ & $78(71 \%)$ & $15(88 \%)$ & 106 (88\%) & $3(13 \%)$ & $12(10 \%)$ & $13(57 \%)$ & $62(55 \%)$ \\
\hline Family history & 25 (93\%) & | 01 (92\%) & 14 (82\%) & $84(69 \%)$ & I (4\%) & $10(9 \%)$ & $15(65 \%)$ & 81 (72\%) \\
\hline Physical WB & 24 (89\%) & 98 (89\%) & $16(94 \%)$ & 108 (89\%) & $9(39 \%)$ & $18(15 \%)$ & $23(100 \%)$ & 109 (96\%) \\
\hline Functional WB & $16(59 \%)$ & $80(73 \%)$ & 14 (82\%) & 88 (73\%) & $3(13 \%)$ & $8(7 \%)$ & $23(100 \%)$ & 104 (92\%) \\
\hline Sexual WB & 10 (37\%) & 48 (44\%) & 8 (47\%) & 49 (40\%) & I (4\%) & 0 & $19(83 \%)$ & 96 (85\%) \\
\hline Social WB & $13(48 \%)$ & 49 (45\%) & 10 (59\%) & 61 (50\%) & I (4\%) & $2(2 \%)$ & $23(100 \%)$ & 103 (9|\%) \\
\hline Emotional WB & $14(52 \%)$ & $59(54 \%)$ & $10(59 \%)$ & $80(66 \%)$ & $2(9 \%)$ & $8(7 \%)$ & $23(100 \%)$ & $105(93 \%)$ \\
\hline Information leaflets (data for & $9(33 \%)$ & $39 / 93(42 \%)$ & $15(88 \%)$ & $52 / 104(50 \%)$ & $5(17 \%)$ & $17 / 99(17 \%)$ & $23(100 \%)$ & 96/98 (98\%) \\
\hline
\end{tabular}

team C missing in colleagues' view)

${ }^{\mathrm{a}}$ Speciality view $=$ number of the speciality that reports giving information about the area. ${ }^{\mathrm{b}}$ Colleagues view $=$ number of colleagues that believe the speciality gives information about the area. 
Table 2b Information roles-speciality versus colleagues view

\begin{tabular}{|c|c|c|c|c|c|c|c|c|}
\hline & \multicolumn{2}{|c|}{ Research nurse role } & \multicolumn{2}{|c|}{ Clinic nurse role } & \multicolumn{2}{|c|}{ Stoma care nurse role } & \multicolumn{2}{|c|}{ Palliative care nurse role } \\
\hline $\begin{array}{l}\text { Total } n \\
\text { Missing data }\end{array}$ & 4 & $\begin{array}{l}46 \\
5\end{array}$ & 3 & $\begin{array}{c}29 \\
2\end{array}$ & 4 & $\begin{array}{l}41 \\
4\end{array}$ & 3 & $\begin{array}{l}33 \\
6\end{array}$ \\
\hline Explaining tests & $2(50 \%)$ & $13(28 \%)$ & $2(67 \%)$ & $8(28 \%)$ & $2(50 \%)$ & $21(51 \%)$ & | (33\%) & $18(55 \%)$ \\
\hline Giving test results & $2(50 \%)$ & $12(26 \%)$ & ( $33 \%)$ & $3(10 \%)$ & $2(50 \%)$ & $21(51 \%)$ & I (33\%) & $19(58 \%)$ \\
\hline Chemotherapy & $3(75 \%)$ & 17 (37\%) & I (33\%) & $4(14 \%)$ & $3(75 \%)$ & $18(44 \%)$ & $2(67 \%)$ & 24 (73\%) \\
\hline $\begin{array}{l}\text { Hormone therapy } \\
\text { (applies to breast teams only) }\end{array}$ & $3(75 \%)$ & $11 / 46(24 \%)$ & $2 / 2(100 \%)$ & $2 / 17(12 \%)$ & N/A & N/A & $\mathrm{N} / \mathrm{A}$ & N/A \\
\hline Prognosis & | (25\%) & $4(9 \%)$ & I (33\%) & I (3\%) & $2(50 \%)$ & $18(44 \%)$ & $3(100 \%)$ & $28(85 \%)$ \\
\hline Clinical trials & $4(100 \%)$ & 39 (85\%) & I (33\%) & I (3\%) & I (25\%) & $13(32 \%)$ & 0 & $13(39 \%)$ \\
\hline Family history & 0 & $5(11 \%)$ & 0 & $2(7 \%)$ & $3(75 \%)$ & $19(46 \%)$ & $2(67 \%)$ & $15(45 \%)$ \\
\hline Physical WB & $3(75 \%)$ & 20 (43\%) & $3(100 \%)$ & 10 (34\%) & $4(100 \%)$ & $30(73 \%)$ & $3(100 \%)$ & 31 (94\%) \\
\hline $\begin{array}{l}\text { Information leaflets (data for team } \\
\mathrm{C} \text { missing in colleagues' view) }\end{array}$ & $3(75 \%)$ & $14 / 29(48 \%)$ & $3(100 \%)$ & $9 / 29(31 \%)$ & $4(100 \%)$ & $32 / 41$ (78\%) & $3(100 \%)$ & $26 / 33(79 \%)$ \\
\hline
\end{tabular}

$\mathrm{N} / \mathrm{A}=$ not applicable. ${ }^{\mathrm{a} S p e c i a l i t y}$ view $=$ number of the speciality that reports giving information about the area. ${ }^{\mathrm{b}}$ Colleagues view = number of colleagues that believe the speciality gives information about the area.

Table 3 Number of professions out of the 14 specialties represented across the 10 teams regularly ${ }^{a}$ covering each information area

\begin{tabular}{|c|c|c|}
\hline Information area & Professional groups regularly providing information & n \\
\hline Giving test results & Surgeon, oncologist, CNS, palliative care physician, gastroenterologist, breast physician & 6 \\
\hline Chemotherapy & Surgeon, oncologist, CNS, research nurse, stoma care nurse, chemo nurse & 6 \\
\hline Hormone therapy (breast teams only) & Surgeon, oncologist, CNS, research nurse, clinic nurse, breast physician, chemo nurse & 7 \\
\hline Prognosis & Surgeon, oncologist, palliative care physician, palliative care nurse, gastroenterologist, chemo nurse & 6 \\
\hline Physical well being & $\begin{array}{l}\text { Surgeon, oncologist, CNS, clinic nurse, research nurse, palliative care physician, stoma care nurse, palliative care } \\
\text { nurse, gastroenterologist, breast physician, chemo nurse, clinical psychologist }\end{array}$ & 12 \\
\hline Functional well being & $\begin{array}{l}\text { Oncologist, CNS, clinic nurse, palliative care physician, stoma care nurse, palliative care nurse, gastroenterologist, } \\
\text { chemo nurse, clinical psychologist }\end{array}$ & 9 \\
\hline Sexual well being & CNS, palliative care physician, stoma care nurse, chemo nurse, clinical psychologist & 5 \\
\hline Social well being & $\begin{array}{l}\text { CNS, clinic nurse, palliative care physician, stoma care nurse, palliative care nurse, gastroenterologist, chemo } \\
\text { nurse, clinical psychologist }\end{array}$ & 8 \\
\hline
\end{tabular}

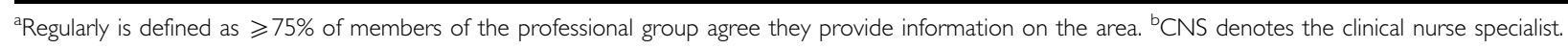

specialists covered the broadest range of information areas $11 / 14$, as well as regularly giving out information leaflets.

Table 4 shows the proportion of members scoring above the threshold of $\geqslant 4$ on the GHQ-12 and the percentage of members with high levels of 'burnout' on each subscale of the MBI for each team and gives a breakdown by speciality. It should be noted that some specialities are not presented in Table 4 in order that anonymity is preserved.

\section{DISCUSSION}

In terms of information coverage, results showed that the surgeons and oncologists had primary responsibilities for conveying information to patients about their investigations, results includ- ing 'bad news', treatment options (surgery, radio-, chemo- and hormone therapy) and prognosis. Multiple professional groups were shown to regularly discuss these areas with the patient. It is not unusual for patients to seek the same piece of information from a series of health professionals, because they forget, because they do not understand the first time around, because they want to be sure, and this underlines the point that it is crucial for members within teams to be sure they are giving the same message, that there is consistency within and across information giving. Further, these vital areas were always backed up by the role of the clinical nurse specialist who it was revealed covered the largest number of information areas identifying them as the thread that runs throughout the patients care in these cancer teams. However, when it came to other information areas, coverage was not always so comprehensive for patients. Interestingly, the two areas where 
Table 4 Distribution of GHQ-12 caseness and high 'burnout' levels on the $\mathrm{MBI}$ subscales by team and by speciality ${ }^{\mathrm{a}}$

\begin{tabular}{|c|c|c|c|c|c|}
\hline & & & & BI subsca & \\
\hline & & $\begin{array}{c}\text { GHQ- } \mathbf{2} \\
\geqslant 4\end{array}$ & $\begin{array}{c}\text { EE } \\
\geqslant 27\end{array}$ & $\begin{array}{c}\text { DP } \\
\geqslant 10\end{array}$ & $\begin{array}{c}\text { PA } \\
\leqslant 33\end{array}$ \\
\hline & Total $n$ & $n(\%)$ & n (\%) & $n(\%)$ & n (\%) \\
\hline Total sample & 144 & $25\left(18^{\mathrm{c}}\right)$ & $39\left(27^{\circ}\right)$ & $27\left(19^{b}\right)$ & $44\left(31^{d}\right)$ \\
\hline By team & & & & & \\
\hline Team A & 15 & I $\left(7^{b}\right)$ & I (7) & 0 & $2(13)$ \\
\hline Team B & 18 & $4(22)$ & $5(28)$ & $3(17)$ & $10(56)$ \\
\hline Team C & 21 & I (5) & $7\left(35^{b}\right)$ & $5\left(25^{b}\right)$ & $9\left(45^{b}\right)$ \\
\hline Team D & 15 & $4(27)$ & $7(47)$ & $8(53)$ & $6\left(43^{b}\right)$ \\
\hline Team E & 13 & ( (8) & $\left(8^{b}\right)$ & ( (8) & $6\left(50^{b}\right)$ \\
\hline Team F & 19 & $5(26)$ & 7 (37) & $3(16)$ & $3(16)$ \\
\hline Team G & 8 & $2(25)$ & $4(50)$ & $3(38)$ & $1(13)$ \\
\hline Team H & 9 & $2(22)$ & $4(44)$ & $2(22)$ & $1(11)$ \\
\hline Team I & 10 & $1\left(11^{b}\right)$ & I (10) & $2(20)$ & $4(40)$ \\
\hline Team J & 16 & $4(25)$ & $2(13)$ & 0 & $2(13)$ \\
\hline By speciail & & & & & \\
\hline Team leaders & 10 & $2(20)$ & $4(40)$ & $3(30)$ & $3(30)$ \\
\hline Surgeons & 27 & $4(15)$ & $6(22)$ & $8(30)$ & $8(30)$ \\
\hline Oncologists & 17 & $2\left(13^{b}\right)$ & $5(29)$ & $5(29)$ & $5(29)$ \\
\hline Radiologists & 23 & $4(17)$ & $5(22)$ & $3(13)$ & $10(43)$ \\
\hline Histopathologists & 18 & $4(22)$ & $5\left(29^{b}\right)$ & $5(28)$ & $11\left(69^{\circ}\right)$ \\
\hline Palliative care physicians & 5 & 0 & I (20) & 0 & I (17) \\
\hline Nurses & 39 & $8(21)$ & $13(33)$ & $4(10)$ & $7(18)$ \\
\hline Radiographers & 5 & I (20) & $1(20)$ & $2(40)$ & 0 \\
\hline
\end{tabular}

$\mathrm{EE}=$ emotional exhaustion, $\mathrm{DP}=$ depersonalisation, $\mathrm{PA}=$ personal accomplishment. ${ }^{a}$ To maintain anonymity data are not presented for specialties with $\leqslant 3$ members. ${ }^{\mathrm{b}}$ One missing data. ${ }^{\mathrm{C}}$ Two missing data. ${ }^{\mathrm{d}}$ Three missing data.

there was least consensus about coverage among the clinical nurse specialists, clinical trials and family history, were the same two areas recognised by the least number of professional groups (3-4/ 14) as part of their information-giving role. These factors coupled together suggest there is potential for weakness in coverage of clinical trials and family history, particularly as some of the specialties taking responsibility for providing this information, for example, palliative care physicians, research nurses, do not routinely see all patients. The clinical nurse specialists were shown to be responsible for covering the psychosocial well being of patients, a role that has traditionally been a nursing domain. However, in many instances in these teams there was no guaranteed fall back for covering these areas were the clinical nurse specialist to be off sick, on annual leave or otherwise unavailable. The potentially weaker areas of information coverage, clinical trials, family history and sexual well being, highlighted by looking at the team members roles are further reinforced by audit results to be presented in a separate paper where the patients treated by the participating study teams were asked to give their views on the information they had received during their care for cancer.

In terms of role clarity the surgeons, oncologists, radiologists and clinical nurse specialists information-giving roles appear to be well defined and understood by other team members. Importantly, there was good agreement within each of these specialities regarding the information regularly given to patients and colleagues' expectations also matched these views. However, agreement was less consistent when the roles of other specialities were reviewed. For example, in both the research and clinic nurse roles there was less than total agreement within each speciality as to the areas they regularly cover with patients and in conjunction with this other team members did not appear to have a consistent view of what these roles entail, similar role ambiguity has previously been described within breast care teams (Jenkins et al, 2001). Discrepancies between the information individuals' cover within a speciality or between that covered by a professional group and team perceptions could be due to a number of factors. For example, the healthcare professional may not feel confident that other team players cover the topic adequately, or it may reflect an attempt by an individual to compensate for uncertainty about their own role by trying to cover all the areas. Some discrepancies will reflect the team having insufficient understanding of a particular profession and this may be more likely with newer subspecialities or professions that are evolving with advances in treatments and technologies. Finally, patients regularly attempting to source information from a team member who would not usually cover a particular topic could force them in to incorporating it into their role while others in their speciality or colleagues in the team do not consider it part of the role. Unchecked these situations can lead to burnout in some individuals or feelings of being undervalued and can result in discontentment, ill will and poor staff morale and certainly there is evidence of this in the current study. There is also the potential for the provision of contradictory information being given to patients about their tests and treatments if team members have little idea about what their colleagues are covering.

The incidence of probable minor psychiatric morbidity overall $(18 \%)$ is identical to the UK general population (Taylor et al, 1995) and marginally above that reported across 72 breast cancer teams (Haward et al, 2003) in which the mental well being of team members appears significantly better than in other studies of cancer clinicians (Ramirez et al, 1996; Taylor et al, 2005) and NHS staff in general (Wall et al, 1997). However, the current study only partially fits this pattern. Averaging across the teams gives a different picture to that represented by a team breakdown. Half the current sample has a case rate in a range $22-27 \%$ which is similar to previous data for other healthcare teams (Mullarky et al, 1999), NHS staff (Wall et al, 1997) and cancer clinicians (Ramirez et al, $1996)$ and one that is above the general population rate $(18 \%$ Taylor et al, 1995). The remaining teams have substantially lower case rates in a range $5-11 \%$, which is even below the most recent rate reported for breast cancer teams (15.7\% - Haward et al, 2003). The experience and effect of team working in these relatively new multidisciplinary configurations was the aim of the current study therefore it is important to appreciate that only some of the cancer teams have a majority of members enjoying good mental health and this is reflected in the MBI results too.

The overall prevalence of high levels of emotional exhaustion and depersonalisation from the subscales of the MBI (27 and $19 \%$, respectively) in the current study are below all previously published rates; US medical staff - rates of $33 \%$ for each subscale (Maslach et al, 1996), less than rates of 32 and 24\%, respectively, for UK consultants (Ramirez et al, 1996), and (for emotional exhaustion only) below the $40 \%$ rate most recently reported at follow-up in the same cohort of UK consultants (Taylor et al, 2005). The overall incidence of $31 \%$ for feelings of low personal accomplishment is just below the US norm but considerably lower than Ramirez et al's (1996) UK data of 39\%. However, breakdown by team clearly shows half of the teams have rates (range $35-50 \%$ ) of high emotional exhaustion greater than the previous findings, while four out of the remaining five teams are markedly lower (range $7-13 \%$ ). This pattern is repeated for feelings of low personal accomplishment with half of the teams showing rates (range 40-56\%) greater than the previous findings while the remaining teams have rates $(11-16 \%)$ considerably lower than the past data. The incidence of high depersonalisation shows only two teams have rates above the previous findings.

The current study revealed a fifth or less (range 13-22\%) within each professional group scored above threshold on the GHQ-12, which is below previously published findings (Ramirez et al, 1996; Taylor et al, 2005) for some of these specialties. Previous samples (Ramirez et al, 1995, 1996; Taylor et al, 2005) have also 
demonstrated the stresses and strains of various professions in terms of burnout on the MBI subscales, notably high rates of emotional exhaustion in clinical and surgical oncologists. Our study found team leaders (who were invariably surgeons) and the nurses appeared prone to high levels of burnout on the emotional exhaustion subscale while it was the radiographers who had the greatest proportion (40\%) reporting high levels of depersonalisation. Feelings of low levels of personal accomplishment were a pervasive problem for the histopathologists (69\%) and a considerable proportion of the radiologists $(43 \%)$.

It seems reasonable to assume that effective MDT working will provide benefits to patients and healthcare professionals working in cancer teams. Evidence has started to accrue showing that certain outcomes are improved (Landheer et al, 2001; Shankar et al, 2001; Van Laethem et al, 2001; Blumberg

\section{REFERENCES}

Blumberg D, Ramanathan K (2002) Treatment of colon and rectal cancer. J Clin Gastroenterol 34: 15-26

Borrill C, West M, Shapiro D, Rees A (2000) Team working and effectiveness in the NHS. British Journal of Health Care Management 6: $364-371$

Boyle FM, Robinson E, Heinrich P, Dunn SM (2004) Cancer: communicating in the team game. ANZ J Surg 74: 477-481

Calman K, Hine D (1995) A Policy Framework for Commissioning Cancer Services. London: Department of Health Expert Advisory Group on Cancer

Carter AJ, West MA (1999) Sharing the burden: teamwork in health care settings. In Stress in Health Professionals, Firth-Cozens J, Payne R (eds) pp 191-202. Chichester: John Wiley \& Sons Ltd

Firth-Cozens J (1999) The psychological problems of doctors. In Stress in Health Professionals, Firth-Cozens J, Payne R (eds) pp 79-91. Chichester: John Wiley \& Sons Ltd

Freeman M, Miller C, Ross N (2000) The impact of individual philosophies of team working on multiprofessional practice and the implications for education. J Int Prof Care 14: 237-247

Goldberg D, Williams P (1988) A User's Guide to the General Health Questionnaire. Berkshire: NFER-Nelson Publishing

Gorney M (1999) The role of communication in the physician's office. Clin Plastic Surg 26: 133

Hall P, Weaver L (2001) Interdisciplinary education and teamwork: a long and winding road. Med Educ 35: 867-875

Harris RL (1997) Consistency of patient information...... is this happening. Cancer Nursing 20: 274-276

Haward R, Amir Z, Borrill C, Dawson J, Scully J, West M, Sainsbury R (2003) Breast cancer teams: the impact of constitution, new cancer workload, and methods of operation on their effectiveness. Br J Cancer 89: $15-22$

Hortobagyi GN (1994) Multidisciplinary management of advanced primary and metastatic breast-cancer. Cancer 74: 416-423

Hughes A, Bradburn J (1996) Consulting consumers. Only human. Health Serv J 106: 30

Jenkins VA, Fallowfield LJ, Poole K (2001) Are members of multidisciplinary teams in breast cancer aware of each other's informational roles? Qual Health Care 10: 70 - 75

Junor EJ, Hole DJ, Gillis CR (1994) Management of ovarian cancer: referral to a multidisciplinary team matters. Br J Cancer 70: $363-370$

Krause HR, Bremerich A, Rustemeyer J (2001) Reasons for patients' discontent and litigation. J Cranio-Maxillofacial Surg 29: 181-182

Landheer ML, Therasse P, van de Velde CJ (2001) The importance of quality assurance in surgical oncology in the treatment of colorectal cancer. Surg Oncol Clin North Am 9: 147-885

Maslach C, Jackson SE, Leiter MP (1996) Maslach Burnout Inventory Manuel: Third Edition. Palo Alto: Consulting Psychologists Press, Inc. and Ramanathan, 2002, Soriano et al, 2002; Haward et al, 2003) but the current study suggests benefits are not always consistent, that advantages do not inevitably result from the adoption of a multidisciplinary approach and that there is room for improvement. We believe more research is needed to better understand how to gain the most from MDT working in cancer. Trusts may need to invest substantial resources in team training to ensure effective teamwork in order to reap the benefits for patients and healthcare professionals.

\section{ACKNOWLEDGEMENTS}

We thank all members of the teams who participated. Cancer Research UK funded this project and its authors.

Miller C, Freeman M, Ross N (2001) Interprofessional Practice in Health and Social Care. Challenging the Shared Learning Agenda. London: Arnold

Mullarky S, Wall TD, Warr PB, Clegg CW, Stride CB (1999) Measures of Job Satisfaction, Mental Health and Job-Related Well-being. Sheffield: Institute of Work Psychology

NHS Executive (1999) Guidance on Commissioning Cancer Services. Improving Outcomes in Gynaecological Cancers, The Manual. London: Department of Health

NHS Executive (2002) Guidance on Commissioning Cancer Services. Improving Outcomes in Breast Cancer, Manual Update. London: Department of Health

NHS Executive (2004) Guidance on Commissioning Cancer Services. Improving Outcomes in Colorectal Cancer, Manual Update. London: Department of Health

Payne R (1999) Stress at work: a conceptual framework. In Stress in Health Professionals, Firth-Cozens J, Payne R (eds) pp 3-16. Chichester: John Wiley \& Sons

Ramirez AJ, Graham J, Richards MA, Cull A, Gregory WM (1996) Mental health of hospital consultants: the effects of stress and satisfaction at work. Lancet 347: 724-728

Ramirez AJ, Graham J, Richards MA, Cull A, Gregory WM, Leaning MS, Snashall DC, Timothy AR (1995) Burnout and psychiatric disorder among cancer clinicians. Br J Cancer 71: 1263-1269

Sainsbury R, Haward B, Rider L, Johnston C, Round C (1995) Influence of clinician workload and patterns of treatment on survival from breast cancer. Lancet 345: 1265-1270

Shankar PJ, Achuthan R, Haray PN (2001) Colorectal sub specialization in a DGH. The way forward!. Colorectal Dis 3: 396-401

Soriano A, Castells A, Lacy AM, Ayuso C, Ayuso JR, Conill C, Delgado S, Fuster J, Garcia-Valdecasas JC, Gines A, Martin M, Maurel J, Miquel R, Molla M, Vilana R, Castellvi-Bel S, Elizalde JI, Pinol V, Pellise M, Biete A, Gascon P, Pique JM (2002) Evaluation of the efficacy and efficiency of a multidisciplinary unit for the treatment of patients with colorectal cancer. Gastroenterol Hepatol 25: 579-584

Taylor C, Graham J, Potts HWW, Richards MA, Ramirez AJ (2005) Changes in mental health of UK hospital consultants since the mid-1990s. Lancet 366: $742-744$

Taylor M, Brice J, Buck N (1995) Household Panel Survey User Manuel. Colchester: University of Essex

Van Laethem JL, Donckier V, Demols A, Franchimont D, Gay F, Van de Stadt J (2001) Treatment of colorectal cancer: a resolute multidisciplinary approach. Rev Med Brux 22: 503-512

Wall TD, Bolden RI, Borrill CS, Carter AJ, Golya DA, Hardy GE, Haynes CE, Rick JE, Shapiro DA, West MA (1997) Minor psychiatric disorders in NHS trust staff: occupational and gender differences. Br J Psychiatr 171: $519-523$ 